\title{
Learned helplessness in reflective and impulsive mentally retarded and nonretarded children
}

\author{
RICHARD M. GARGIULO, PATRICIA S. O'SULLIVAN, and NANCY J. BARR \\ University of Alabama at Birmingham, Birmingham, Alabama
}

\begin{abstract}
Forty-four educable mentally retarded and 44 nonretarded children of equivalent mental age were assessed with the Intellectural Achievement Responsibility (IAR) questionnaire. The students' attributions on the IAR identified 35 mildly retarded and 36 nonretarded subjects who could be categorized as helpless or as mastery oriented. The retarded learners were significantly more helpless than were their nonretarded peers. The cognitive disposition of these 71 individuals was determined via Kagan's Matching Familiar Figures Test (MFFT). No difference was observed in the cognitive style of retarded and that of nonretarded pupils, nor did reflective and impulsive subjects perform significantly differently on any of the four indices of helplessness. MFFT error and latency scores were not significantly correlated with measures of helplessness. The findings were interpreted as suggesting (1) that it is unlikely that cognitive disposition affects learned helplessness, and (2) the importance of environmental considerations in explaining the phenomenon of learned helplessness in mildly retarded learners.
\end{abstract}

The phenomenon of learned helplessness was first investigated systematically by Seligman and Maier (1967) and was subsequently elaborated on and expanded (Abramson, Seligman, \& Teasdale, 1978; Maier \& Seligman, 1976). Learned helplessness has generally been conceptualized as the perception and expectation of responseoutcome independence, that is, that an individual cannot control the outcome of an event he or she experiences. This absence of contingency has been associated with debilitating motivational, cognitive, and emotional deficits (Abramson et al., 1978).

Research evidence has related learned helplessness to observable cognitive and behavioral effects. According to Weisz (1979), these effects, which in some instances have served as operational definitions of helplessness, include attributions for failure to stable or invariant factors, especially insufficient ability, and deficits in both voluntary response initiation and perseverance following failure or failure feedback. One group of individuals in particular, mentally retarded children, appears to be especially susceptible to learned helplessness (Weisz, 1981b, 1982). This observation is valid even when retarded and nonretarded students are of comparable cognitive ability (Raber \& Weisz, 1981).

Several reasons have been extended as to why the mentally retarded are particularly susceptible to learned helplessness. The first of these environmental factors is their frequent exposure to failure (Weisz, 1979). Retarded children experience what Zigler (1971) has portrayed as "a lifetime characterized by frequent confrontations with

Address correspondence to Richard M. Gargiulo, Department of Special Education, University of Alabama at Birmingham, University Station, Birmingham, AL 35294. tasks with which [they] are intellectually ill-equipped to deal"' (p. 83). As Weisz (1981b) astutely observed, such a profile "bears a marked resemblance to the successive failures used by investigators to induce helplessness in experiments with children"' (p. 499). A second plausible explanation for heightened susceptibility is negative performance feedback from teachers, which is generally indicative of inadequate ability (Raber \& Weisz, 1981). In addition to this helplessness-inducing pattern of feedback, attributional and expectancy biases of adults toward the retarded and resultant helplessness-condoning behavior also have been hypothesized to foster helplessness (Weisz, 1981a). Although the retarded are more susceptible to helplessness than are their nonretarded counterparts, helplessness deficits only materialize at relatively mature mental ages (Weisz, 1979, 1981b), thereby suggesting that the retarded child's helplessness-inducing experiences are cumulative.

Individual learner characteristics are an important variable in mediating the effects of learned helplessness. "The occurrence of learned helplessness," according to Winefield (1982), "seems to depend on a variety of individual difference variables"' (p. 262). One dimension that may mediate learned helplessness is conceptual tempo or cognitive style. Messick (1984) recently reviewed the significance of cognitive style and its implication for education and human development. He noted, in particular, that "styles function in part as controlling mechanisms determining an individual's characteristic regulation and control of attention, impulse, thought, and behavioral expression in diverse areas" (p. 64). The concept of a reflective or impulsive cognitive style (Kagan, 1965) - that is, how carefully a student evaluates his or her cognitive products before offering a response-is one aspect of chil- 
dren's learning that may be especially germane to the phenomenon of learned helplessness. Recently, Swartz, Purdy, and Fullingim (1983) identified impulsivity and the accompanying lack of reflectivity as features common to learned helplessness. Other researchers also have alluded to the possible contribution of cognitive style in explaining differences between helpless and nonhelpless, or mastery-oriented, children (Diener \& Dweck, 1978).

The influence of cognitive style on learned helplessness, however, apparently has not been investigated. No reports were found examining this relationship in either retarded or nonretarded populations, despite the suggestion that cognitive style affects the classroom performance of both handicapped (Keogh, 1971) and nonhandicapped students (Messer, 1970), and that special educators frequently work with children exhibiting impulsive learning strategies (Keogh, 1971). The intent of the present research, therefore, was to explore the relationship of reflectionimpulsivity to learned helplessness in educable mentally retarded (EMR) and nonretarded students of equivalent mental age. It was anticipated that impulsive individuals and EMR children would be significantly more helpless.

\section{METHOD}

\begin{abstract}
Subjects
Eighty-eight subjects, 44 mildly mentally retarded ( 26 boys, 18 girls) and 44 nonretarded children ( 26 boys, 18 girls), participated in the experiment. The EMR subjects were randomly chosen from special education classrooms within a suburban school system. The nonretarded youngsters were selected from elementary classrooms located in the same school district. The children were predominantly Caucasian and middle class. All subjects were free from observable physical or sensory handicaps. The mentally retarded children had mean chronological and mental ages of $13.95(S D=1.84)$ and $9.18(S D=1.70)$, respectively, whereas the nonretarded subjects exhibited mean chronological and mental ages of $8.80(S D=.84)$ and $9.27(S D=1.66)$, respectively. Mean IQ for each group was $68.12(S D=7.76)$ and $102.06(S D=13.50)$, respectively.
\end{abstract}

\section{Instruments}

The Matching Familiar Figures Test (MFFT) was developed by Kagan, Roseman, Day, Albert, and Phillips (1964) to assess impulsive and reflective cognitive styles in children. This visual discrimination assessment consists of 14 sets of familiar pictures (e.g., teddy bear, telephone), two practice items, and 12 test items. The individual is shown a standard stimulus and six similar variants and is required to select a picture identical to the standard. The standard and possible choices are presented simultaneously. If the subject makes an incorrect choice, he/she is required to choose again until the correct stimulus is chosen. Latency to the first response and the total number of errors are recorded. A reflective cognitive tempo is defined as a score above the median in response time and below the median in errors. An impulsive cognitive style is designated when a student scores below the median in response time and above the median in errors. Individuals scoring below the median in both latency and errors are considered fast/accurate, whereas scoring above the median in both latency and errors results in the label of slow/inaccurate.

The four additional assessments and the accompanying scoring procedures incorporated in this experiment have been fully described in a companion investigation (Gargiulo, O'Sullivan, \& Barr, in press). These tasks included the student-completed Intellectual Achievement Responsibility (IAR) questionnaire (Crandall, Katkovsky, \& Crandall, 1965), the teacher-completed Helpless Behavior Checklist (HBC; Weisz, 1981b), a measure of perseverance subsequent to failure (Weisz, 1979), and a three-part response initiation task derived from the research of Floor and Rosen (1975) and Weisz (1979).

\section{Procedure}

After obtaining informed parental consent and establishing rapport, a female experimenter individually assessed each subject in a small examination room located in each school. Approximately 2 weeks prior to administration of the dependent measures, the EMR subjects received the Peabody Picture Vocabulary Test (PPVT; Dunn \& Dunn, 1981). Upon determining the mental age of the retarded subjects, nonretarded children also were assessed with the PPVT and matched (to within 1 month) on mental age with the EMR children. The proportion of boys and girls in each group was maintained.

The experimental procedure was inaugurated with the "name" and “chair" components of the response initiation task (Weisz, 1979). The subject was also exposed to a third ("pencil") response measure (Floor \& Rosen, 1975).

So that we could assess perserverance, each pupil was asked to complete two puzzles according to conditions described by Weisz (1979). Prior to the pupil's return to his/her classroom, he/she received the MFFT and was orally administered the IAR in accordance with the instructions. Subjects were thanked for their participation and requested not to discuss the experiment with classmates.

Teachers received a copy of the Helpless Behavior Checklist for each student who participated in the study. They were asked to complete the questionnaire and return it to the investigator via a postage-paid envelope in 3 days.

To control for order of testing, after the first two response initiation measures, the order of presentation of the MFFT, IAR, and the perseverance and "pencil" tasks was randomly determined for both retarded and nonretarded children.

Helplessness pretraining procedures were not incorporated in the present investigation. Studies employing this design are, in effect, assessing only the subjects' differential sensitivity to the helplessness training procedures. They do not measure the extent to which pupils naturally manifest learned helplessness (Butkowsky \& Willows, 1980). Similarly, Coyne, Metalsky, and Lavelle (1980) argued that all human helplessness experiments are in actuality investigations of experimenterinduced failure. Thus, no attempt was made to procedurally elicit learned helplessness. Rather, helplessness was determined by the students' performance on the IAR. Evidence from Diener and Dweck $(1978,1980)$ suggests that the number of low-effort attributions for negative outcomes on the IAR serves as a particularly refined index of learned helplessness. This relative emphasis, therefore, was used as the criterion for categorizing subjects as helpless or as mastery oriented. A median split was conducted on those 10 items of the IAR that specifically assess children's attributions for failure to low effort. Students scoring above the median were designated mastery oriented, pupils scoring below the median were labeled helpless, and subjects whose score was at the median were excluded from further participation.

\section{RESULTS}

The median split (median $=7$ ) on IAR attributions for failure to low effort identified 37 helpless students (mental age $[\mathrm{MA}]=9.15$ ) and 34 mastery-oriented children $(\mathrm{MA}=9.30)$. Seventeen individuals were excluded for scoring at median. Results, therefore, are based upon 71 children: 35 retarded $(\mathrm{MA}=9.23)$ and 36 nonretarded $(\mathrm{MA}=9.33), 42$ males $(\mathrm{MA}=9.20)$ and 29 females $(\mathrm{MA}=9.26)$. Equivalence of mental age was confirmed by $t$ tests. The categorization of the children as helpless or as mastery oriented on the basis of their IAR scores 
Table 1

Mean Helplessness Scores for Mentally Retarded and Nonretarded and for Male and Female Subjects

\begin{tabular}{|c|c|c|c|c|c|c|c|c|c|}
\hline \multirow[b]{2}{*}{ Group } & \multirow[b]{2}{*}{$n$} & \multicolumn{2}{|c|}{$\begin{array}{l}\text { Response } \\
\text { Initiation }\end{array}$} & \multicolumn{2}{|c|}{ Perseverance } & \multicolumn{2}{|c|}{ HBC } & \multicolumn{2}{|c|}{ IAR } \\
\hline & & Mean & $S D$ & Mean & $S D$ & Mean & $S D$ & Mean & $S D$ \\
\hline Retarded & 35 & 1.61 & .74 & .114 & .322 & 14.80 & 4.45 & 21.22 & 3.94 \\
\hline Nonretarded & 36 & 2.48 & .69 & .527 & .506 & 4.55 & 6.38 & 25.13 & 3.73 \\
\hline Male & 42 & 2.06 & .83 & .285 & .457 & 10.09 & 7.42 & 23.14 & 4.39 \\
\hline Female & 29 & 2.04 & .85 & .379 & .493 & 8.89 & 7.74 & 23.31 & 4.20 \\
\hline
\end{tabular}

Note-HBC $=$ Helpless Behavior Checklist. IAR = Intellectual Achievement Responsibility questionnaire.

was corroborated by their performance on the response initiation measure, perseverance task, and the HBC (Gargiulo et al., in press).

A $2 \times 2$ (group $\times$ sex) multivariate analysis of variance procedure, utilizing Hotelling's criteria, indicated significant differences between retarded and nonretarded learners on the IAR and measures of response initiation, perseverance, and teacher perception of helplessness $[F(4,64)=23.31, p<.001]$. In each instance, univariate post hoc analyses revealed that the mildly mentally retarded children demonstrated significantly greater helplessness $(p<.001)$. Boys and girls, however, did not significantly differ in their performance $[F(4,64)=.289$, $p=.883]$, and no significant interactions were evidenced. Table 1 presents the means and standard deviations for group and sex differences on the composite response initiation measure, perseverance task, HBC, and IAR.

A $2 \times 2$ (group $\times$ sex) MANOVA revealed an absence of significant differences in errors and latency on the MFFT for both retarded and nonretarded children as well as for males and females $[F(2,66)=.116, p=.891$; $F(2,66)=.873, p=.422$, respectively].

A double median split was conducted (Kagan, 1966) for all 71 subjects. Median latency to the first response was $13.5 \mathrm{sec}$, and 17 was the median number of total errors. Error scores ranged from 2 to 37 for retarded subjects and from 6 to 32 for nonretarded individuals. Latency ranged from $5.5 \mathrm{sec}$ to $44.0 \mathrm{sec}$ and from $6.0 \mathrm{sec}$ to $30.0 \mathrm{sec}$ for each group, respectively. The Kagan procedure identified 21 reflectives $(11$ mentally retarded and 10 nonretarded), 20 impulsives (10 in each group), 12 fast/accurate students ( 6 in each group), and 9 slow/ inaccurate individuals (4 mentally retarded and 5 nonretarded). Those subjects whose scores were on the me- dian for either latency or errors were eliminated from further analysis $(n=9)$.

The performance of children identified as reflective/ impulsive and retarded/nonretarded was investigated via a $2 \times 2$ (style $\times$ group) multivariate procedure. Significant differences were not observed in the performance of reflective (MA $=9.32)$ and impulsive $(\mathrm{MA}=9.33)$ subjects on any of the helpless measures $[F(4,34)=6.73$, $p=.615]$. Retarded $(n=21)$ and nonretarded $(n=20)$ pupils, however, who were either impulsive or reflective significantly differed on all helplessness tasks $[F(4,34)=$ $34.65, p<.001]$. None of the available interactions were significant. Table 2 provides the mean scores for both groups of subjects on the four assessments of helplessness.

Finally, correlation coefficients for the entire sample were established between MFFT error and latency scores and the various indices of helplessness. Neither error nor latency was significantly related to any of the helplessness assessments.

\section{DISCUSSION}

In comparison to nonretarded students, the EMR pupils did not respond more rapidly or with less accuracy on the MFFT. This observation corroborates the findings of Borys and Spitz (1978) and would seem to suggest that, when equated on mental age, the cognitive disposition of mentally retarded children parallels that of nonretarded youngsters. This result could further be interpreted as implying that on this visual search task, mentally retarded persons employed cognitive strategies similar to those of nonretarded individuals, yet a distinction between perceptual and cognitive functions cannot always be clearly articulated.

The EMR children were particularly susceptible to helplessness. When compared with their nonretarded peers, the EMR subjects took less personal responsibility for their behavior, regardless of whether they were successful or not. Their ascriptions did not reflect attributions to effort or ability but rather emphasized luck or the behavior of significant others. Furthermore, they were less persistent at a task and initiated fewer

Table 2

Mean Helplessness Scores for Reflective and Impulsive and for Mentally Retarded and Nonretarded Subjects

\begin{tabular}{|c|c|c|c|c|c|c|c|c|c|}
\hline \multirow[b]{2}{*}{ Group } & \multirow[b]{2}{*}{$n$} & \multicolumn{2}{|c|}{$\begin{array}{l}\text { Response } \\
\text { Initiation }\end{array}$} & \multicolumn{2}{|c|}{ Perseverance } & \multicolumn{2}{|c|}{ HBC } & \multicolumn{2}{|c|}{ IAR } \\
\hline & & Mean & $S D$ & Mean & $S D$ & Mean & $S D$ & Mean & $S D$ \\
\hline Reflective & 21 & 1.83 & .96 & .333 & .483 & 8.42 & 6.91 & 23.00 & 3.75 \\
\hline Impulsive & 20 & 2.16 & .67 & .400 & .502 & 8.50 & 6.32 & 22.05 & 4.89 \\
\hline Retarded & 21 & 1.60 & .81 & .142 & .359 & 13.95 & 3.40 & 20.47 & 4.32 \\
\hline Nonretarded & 20 & 2.40 & .69 & .600 & .500 & 2.70 & 3.16 & 24.70 & 3.85 \\
\hline
\end{tabular}


responses in equivocal situations. Teacher assessment of relevant classroom performance yielded further support of the susceptibility of the retarded students. This pronounced tendency toward helplessness is congruent with the research findings of Reynolds and Miller (1985) and Weisz (1981b) and suggests that school environmental factors (Weisz, 1982) are salient dimensions when examining the phenomenon of learned helplessness in mildly retarded learners. These results further seem to suggest that mentally retarded children manifest both a "personal" and "chronic" form of helplessness (Abramson et al., 1978). Even assignment to a special education classroom, wherein, according to Spitz (cited in Weisz, 1982), students are sheltered from failure experiences and teachers dispense success and positive feedback (MacMillan, 1971), failed to remedy their helplessness.

Contrary to expectation, the children's cognitive style did not influence performance on tasks of helplessness. The absence of a significant difference between reflective and impulsive individuals is counter to the theorizing of Swartz et al. (1983) and suggests that it is unlikely that cognitive disposition contributes to the generally poor academic performance of the helpless subjects. Dweck and Bush (1976), however, offer one plausible explanation for the observed difference in helplessness between mastery-oriented and helpless students. Although the arguments cited in their research were originally extended to explain sex differences, they also appear germane to these two types of learners. Building upon their foundation, one could speculate that, as a result of previous school experiences and interaction patterns, the behavior of mastery-oriented children denotes a reliance on internal standards of excellence in contrast to the helpless subjects' dependency on the external opinions of significant others. Hence, when assessing quality of performance, helpless individuals are more other-directed, focusing on the uncontrollable variable of evaluative attributions of important others and interpreting this feedback as a condemnation of abilities, whereas mastery-oriented children maintain relatively independent, autonomous standards.

Although this investigation was unable to offer a cognitive explanation for learned helplessness in retarded and nonretarded children, researchers should continue in their attempts to identify those factors that may mitigate students' expression of ability and, thus, adversely impact school performance. An additional fruitful endeavor would be developing strategies for immunizing children from the debilitating effects of helplessness and, when appropriate, developing tactics for remediating it.

\section{REFERENCES}

Abramson, L., Seligman, M., \& Teasdale, J. (1978). Learned helplessness in humans: Critique and reformulation. Journal of Abnormal Psychology, 87, 49-74.

BORYs, S., \& SPITZ, H. (1978). Reflection-impulsivity in retarded adolescents and nonretarded children of equal MA. American Journal of Mental Deficiency, 82, 601-604.

BuTkowsKY, I., \& WILLOWs, D. (1980). Cognitive-motivational characteristics of children varying in reading ability: Evidence for learned helplessness in poor readers. Journal of Educational Psychology, 72, 408-422.

Coyne, J., Metalsky, G., \& Lavelle, T. (1980). Learned helplessness as experimenter-induced failure and its alleviation with attentional redeployment. Journal of Abnormal Psychology, 89, 350-357.

Crandall, V., Katkovsky, W., \& Crandall, V. (1965). Children's beliefs in their own control of reinforcements in intellectual-academic achievement situations. Child Development, 36, 91-109.

DIENER, C., \& DWECK, C. (1978). An analysis of learned helplessness: Continuous changes in performance, strategy, and achievement cognitions following failure. Journal of Personality \& Social Psychology, 36, 451-462.

DIENER, C., \& DWECK, C. (1980). An analysis of learned helplessness: II. The processing of success. Journal of Personality \& Social Psychology, 39, 940-952.
Dunn, L., \& DunN, L. (1981). Peabody Picture Vocabulary Test. Circle Pines, MN: American Guidance Service.

DwECK, C., \& BuSH, E. (1976). Sex differences in learned helplessness: I. Differential debilitation with peer and adult evaluators. Developmental Psychology, 12, 147-156.

FLOOR, L., \& RoSEN, M. (1975). Investigating the phenomenon of helplessness in mentally retarded adults. American Journal of Mental Deficiency, 79, 565-572.

Gargiulo, R., O'Sullivan, P., \& Barr, N. (in press). Assessment of learned helplessness in mentally retarded and nonretarded children: A methodological investigation. Journal of Human Behavior \& Learning.

KaGAN, J. (1965). Impulsive and reflective children. In J. Krumboltz (Ed.), Learning and the educational process (pp. 133-161). Chicago: Rand McNally.

KAGAN, J. (1966). Reflection-impulsivity: The generality and dynamics of conceptual tempo. Journal of Abnormal Psychology, 71, 17-24.

Kagan, J., Roseman, B., Day, D., Albert, J., \& Phillips, W. (1964). Information processing in the child: Significance of analytic and reflective attitudes. Psychological Monographs, 78(1, Whole No. 578).

KEOGH, B. (1971). Hyperactivity and learning disorders: Review and speculation. Exceptional Children, 38, 101-109.

MacMillan, D. (1971). The problem of motivation in the education of the mentally retarded. Exceptional Children, 37, 579-586.

Maier, S., \& Seligman, M. (1976). Learned helplessness: Theory and evidence. Journal of Experimental Psychology: General, 105, 3-46.

MESSER, S. (1970). The effect of anxiety over intellectual performance on reflection-impulsivity in children. Child Development, 41, 723-735.

Messick, S. (1984). The nature of cognitive styles: Problems and promise in educational practice. Educational Psychologist, 19, 59-74.

RABER, S., \& WEISZ, J. (1981). Teacher feedback to mentally retarded and nonretarded children. American Journal of Mental Deficiency, 86, 148-156.

ReYNolds, W., \& Miller, K. (1985). Depression and learned helplessness in mentally retarded and nonmentally retarded adolescents: An initial investigation. Applied Research in Mental Retardation, 6, 295-306.

Seligman, M., \& MaIER, S. (1967). Failure to escape traumatic shock. Journal of Experimental Psychology, 74, 1-9.

Swartz, J., Purdy, J., \& Fullingim, B. (1983). Learned helplessness in normal and learning disabled children: Emerging issues and explanations. Advances in Learning \& Behavioral Disabilities, 2 , 265-280.

WEISZ, J. (1979). Perceived control and learned helplessness in mentally retarded and nonretarded children: A developmental analysis. Developmental Psychology, 15, 311-319.

WEISZ, J. (1981a). Effects of the "mentally retarded" label on adult judgments about child failure. Journal of Abnormal Psychology, 90, 371-374.

WEISZ, J. (1981b). Learned helplessness in black and white children identified by their schools as retarded and nonretarded: Performance deterioration in response to failure. Developmental Psychology, 17, 499-508.

WEISZ, J. (1982). Learned helplessness and the retarded child. In E. Zigler \& D. Balla (Eds.), Mental retardation: The developmentaldifference controversy (pp. 27-40). Hillsdale, NJ: Erlbaum.

WiNEFIELD, A. (1982). Methodological difficulties in demonstrating learned helplessness in humans. Journal of General Psychology, 107, 255-266.

ZIGLER, E. (1971). The retarded child as a whole person. In H. Adams \& W. Boardman (Eds.), Advances in experimental clinical psychology (pp. 47-121). Elmsford, NY: Pergamon Press.

(Manuscript received for publication February 20, 1987.) 